\title{
Digitizing the Ceylon Collections: A Case Study of the Library, Eastern University, Sri Lanka
}

Gayathiri Navirathan ${ }^{1}$, Mariapillai Jeyakananthan ${ }^{2}$

\begin{abstract}
The digitization is a tactical way of preservation and it becomes an ultimate need to preserve and conserve a record for future use. Even though, the digital preservation is indeed a very challenging task for the library of Eastern University, Sri Lanka (EUSL library) and the digitization process has become a practical necessity in this digital era. Hence, the study describes an initiation towards digitization in order to preserve the precious Ceylon Collections of EUSL library which endures the value and importance of Ceylon Collections for the benefit of various users and also to avoid those collections remain ambiguous and hidden. The current research design is a case study and the research instruments such as observation and focus group interview were used. The DSpace open source software was selected for the digitization processes. The focus group interview was conducted to explore the current usage and expectation of the users and it revealed that the Ceylon Collections services are very essential for users. The study was initiated by two professionals (who are also the authors of this paper) without proper training on functioning and technicalities of DSpace. With testing server, researchers could successfully implement the digital collection and today its collection is totaling to 2000 items. Through digitization, the Ceylon Collections move to a much broader audience and therefore the Ceylon Collections could be accessed significantly through the web and preserved for future generations. Even though, there were challenges during digitization process the work has been completed successfully and the digitized Ceylon Collections could be maintained as a digital repository of Ceylon Collections which are capable to access through the library website. Thus, every user would able to access those Ceylon Collections.
\end{abstract}

Keywords: Ceylon Collections, Conservation, Digitization, DSpace, Open source software, Preservation, Rare collection, Special collections

1 Senior Assistant Librarian, Eastern University, Sri Lanka. Email: t_gaya_thiri@yahoo.com, (1D https://orcid.org/0000-0002-5604-3873

2 System Analyst cum Programmer, Eastern University, Sri Lanka. Email: mjeya81@gmail.com, (D) https://orcid.org/0000-0001-6064-819X

Received: 26 March 2018, Accepted revised version: 3 July 2018.

This work is licensed under a Creative Commons Attribution-ShareAlike 4.0 International License. 


\section{Introduction}

The Eastern University, Sri Lanka is a centre of excellence for higher education in Sri Lanka. Accordance with the mission of the Eastern University, Sri Lanka, to be a centre of excellence in higher education, the library of Eastern University (EUSL library) is mounting as an exclusive unit in the teaching, learning and research activities of the university. The EUSL library is to support the university's commitment to excellence in higher education by providing quality information services to students, staff and the community at large and ensuring a continuous free flow of information to the users.

As the heart of EUSL, the EUSL library provides valuable information resources for the users of Eastern University. One of the main information sources are Ceylon Collections which prevail as centuries collections too. The Ceylon Collections such as "Sethu Puranam" by "Sri Arumuganavalar" (1866), "Tholkappium" by "Nachchinarkiniyar" (1885), "Chemistham" by "Wesu Pandithar" (1875), "Palamirtham" by "Sank. Sivapragasa Pandithar" (1903) could be considered as rare collections available in the EUSL library as well as the whole country.

In the EUSL library, the library materials struggle with slow decay caused by the acidity of paper, infestation of insects, improper handling by users, improper storage facilities and excessive temperature, humidity and polluted air which is unavoidable. As the Ceylon Collections are unique collections including century's documents, they are susceptible to further damage by mechanical handling when each and every original document is undergone for the user access in EUSL library and also, there is a requirement for wider access of those valuable Ceylon Collections by different users. To ensure the Ceylon Collections remain available to all library users, the library should engage with the processes to conserve and preserve the material and make the collections more durable.

As the library's key role as an information supplier to the clientele in this digital age, there is an emergent need to incorporate digital information resources along with printed information resources. For the benefit of users at EUSL library, the process of digitization has to be started to reach the 
wider access of audience. Hence, the digitization of Ceylon Collections makes an effort to solve prevailing problems.

\section{Digital Preservation and its Importance}

Preservation is the conservation of knowledge. Digital preservation refers to the management of digital information resources. According to Chattopadhyay (2006), digital preservation is defined as long-term, error-free storage of digital information, with means for retrieval and interpretation, for the entire time span that the information is required for. Therefore, digitization is one of the methods of making library collections more longlasting.

Digitization is the process of transforming the traditional library materials into an electronic form which can be stored and manipulated by a computer. Digitization ensures the use of special collections such as Ceylon Collections by enormous users unlike the common library collections. Once these collections are accessible, they become an essential resource. Without digitization, special collections remain ambiguous and hidden. Through digitization, these collections move to a much broader audience and therefore within the researched area Ceylon Collections could be accessed greatly through the web and preserved for future generations. It entails the digital information over time and ensures the protection of information enduring value for access by present and future generations.

Even though the digital preservation is indeed a very challenging task for EUSL library, digitization has become a practical necessity and as technology intrusions to enhanced access of information resources and it enhances the dissemination of information resources which are accessible anywhere at any time needed. Therefore, the digitization of Ceylon Collections is an essential need in this twenty-first century as long-term use and increased access is advantageous for the succeeding generations. Hence, the study explores an initiation towards digitization in order to preserve the precious Ceylon Collections of EUSL library which endure the value and importance of Ceylon Collections for the benefit of various users. 
In the present digital information era, the libraries are facing inevitability to adopt software and technological tools to fully satisfy the library users as well as to manage and protect the library resources. Especially the libraries in developing countries have insufficient budget for experimentation and implementation of technology and also procurement of resources. In this context, digital repositories have emerged as an alternative publishing platform to the academic world. There are numbers of digital repositories software available as "Open Source" as well as "Proprietary". Mittal and Mahesh (2008) discussed about using open source in setting up digital libraries. According to the above researchers employing open source software is very easy and they provide clear awareness, training facilities and most importantly the negligible costs. Today more libraries are using open source software rather than commercial or custom-made solutions. Therefore, EUSL library has decided to use DSpace open source software for the digitization processes.

\section{Research Objectives}

General objective of the study is to digitize Ceylon Collections which are available in EUSL library. Specific objectives of the study were to:

i. Conserve and preserve valuable Ceylon collections by means of digitization for researchers and academics use.

ii. Compile bibliographic details of Ceylon Collections which showcase their value.

iii. Identify the challenges during the process of digitization of Ceylon Collections.

\section{Literature Review}

International Federation of Library Associations and Institutions (IFLA) (2014) mentioned that, digitization of a rare and unique collection is complex as it is important to maintain physical, intellectual and contextual relationships both within single objection and collection as a whole. Gangabadachchchi and Amarasiri (2006) stated that the printed material continue to deteriorate rapidly and therefore, the digitization would rectify these problems and assist in preserving the originals thus reformatted copies could be used. Reformatting the damaged or endangered books or document is an effective and economic conservation measure. Simultaneously, 
digitization helps to increase accessibility of these material. Further, strengthening above statement, Jenkins (2012) reported that, preservation of digital items certainly more intensive in terms of time and resources than physical preservation but it has the potential of keeping all identified items available to all who deserve to interact with them for far longer. Once collections have been digitized, they are removed from geographical boundaries.

Dilroshan (1995) stated that, University Grants Commission - Sri Lanka provided one microcomputer to eight university libraries to fulfil the ground level work of automation in 1991. As a primary step of creating digital libraries in the university sector, University of Colombo took the main role to train university librarians with the collaboration of INASP in the year 2009. Training was given in India. Selected university librarians received the training and they were expected to implement digital library system for respective university libraries (Hindagolla, 2013). After receiving technical and human resource training on digital library, initiating and developing projects had been increased in university libraries in Sri Lanka. Many university libraries initiated digitalization projects with the mission of fullfledged digital libraries because universities in Sri Lanka are at a competitive stage to upgrade their national university rank in web metrics. Therefore, most specifically universities are paying attention to create their institutional repositories to enhance their service as well as create a wider user access (Kodikara, Seneviratne \& Punchihewa, 2014). Most of the university libraries implement the digital libraries using DSpace open source in Linux platform. As an initial stage, with permission given by the university authorities, university copyrighted documents were deposited into the digital repository such as university research publications, abstract of university thesis, academic staff members' research publications (Hindagolla, 2013). Another mass digital library project has started in Palm Leaf Manuscript Study and Research Library at Faculty of Social Sciences at the University of Kelaniya. To date, over hundred thousand $(100,000)$ pages have been digitized. A website has been already developed with introductory details and the database of digitized manuscripts will be online in due course. DSpace software platform is used to create the digital library by following Metadata standards drawn from Dublin Core (Ranasinghe \& Dilruk, 2013). 


\section{Methodology}

The current study is a descriptive study and the research design is a case study. Ranjith Kumar (2014) stated that, the case study design is based upon the assumption that the case being studied is typical of cases of a certain type and therefore a single case can provide insight into the events and situations prevalent in a group from where the cases can be drawn. He also mentioned that, the focus groups are a form of strategy in qualitative research in which attitudes, opinions or perceptions towards an issue, product, service or programme are explored through a free and open discussion between members of a group and the researchers. As such, the case study was carried out following manner.

\section{Step 1-Focus Group Interviews}

As an initial stage focus group interview was used to explore the current usage and expectation of the users. Fivee interviews with 50 participants were carried out from April to May 2018. Participants were selected randomly and each focus group lasted about 10-20 minutes and was audio recorded. All responses were separated to individual statements and categorized according to the research questions (Table 1).

Table 1. Focus group participant responses

\begin{tabular}{ll}
\hline General question & Summary of responses \\
\hline \multirow{2}{*}{ Accessibility } & $\begin{array}{l}\text { The physical library has not enough space. } \\
\text { Users want extended library hours. } \\
\text { All user groups desire off-campus access. }\end{array}$ \\
$\begin{array}{c}\text { Organization of } \\
\text { information }\end{array}$ & $\begin{array}{l}\text { Users are unaware of the full range of resources and } \\
\text { services }\end{array}$ \\
$\begin{array}{c}\text { Ease of } \\
\text { searching/use }\end{array}$ & Difficult to find exact resources \\
$\begin{array}{c}\text { Customer support } \\
\text { Future expectation }\end{array}$ & Limited \\
\hline
\end{tabular}

Overall, the focus group discussions revealed that Ceylon Collections services are very essential for users and most of the users expect online access and request more online help to assist in search for information and 
improve their information seeking skills. The results have implications for academic libraries providing digital services in a networked environment.

\section{Step 2 - Selection of Collections}

The material which has to be digitized was identified as the Ceylon Collections available in EUSL library. At the same time the condition of the documents was recorded. Once the content selection process was completed, the background historical and technical information of Ceylon Collections with details were compiled.

\section{Step 3 - Assuring Hardware and Software Availability}

A comprehensive information technology infrastructure was required for creating and managing digital repositories. The basic requirement was a well-established and planned network environment in the library. At Eastern University nearly 800 terminals are connected through local area network with high-speed multiprocessor servers and powerful workstations for high data transfer rate over the Intranet. Following technological infrastructures were available when the digitization process was initiated at EUSL.

- DELL Power edge T110 processor (3.6 GHz) based tower model server system with 4GB RAM and RAID storage system.

- Everyday incremental backup is done with Dropbox.

- Canon flatbed scanners.

- Adobe Acrobat 7.0 professional for scanned image processing.

\section{Step 4 - Selection of Software}

The last decade a great number of digital library softwares have been developed and published on open-source platform. Since, variety of available software systems available, it is somewhat difficult to select a software when an organization plans to build a repository infrastructure to host its collections. Open Society Institute (2004) has published guideline for selecting open-source repository software, based on the features and its benefits. According to the Open Society Institute guide the following three restrictions in order to select the repository software systems.

- Publicly available using an open-source license

- Compliant with the Open Archives Initiative Protocol for Metadata Harvesting (OAI-PMH) 
- Have a large number of installations worldwide

Five repository software systems were selected for the comparative study and details are summarised in Table 2.

Table 2. Selected repository software systems for the comparative study

\begin{tabular}{|c|c|c|c|}
\hline Software & Developer & License & Website \\
\hline D-Space & $\begin{array}{l}\text { MIT Libraries and } \\
\text { Hewlett-Packard } \\
\text { Labs }\end{array}$ & $\begin{array}{l}\text { BSD open source } \\
\text { license }\end{array}$ & http://www.dspace.org/ \\
\hline $\begin{array}{l}\text { Fedora } \\
\text { Commons }\end{array}$ & $\begin{array}{l}\text { Cornell University } \\
\text { and the University } \\
\text { of Virginia } \\
\text { Library }\end{array}$ & $\begin{array}{l}\text { Apache License, } \\
\text { Version } 2.0\end{array}$ & http://www.fedoracommons.org/ \\
\hline Greenstone & $\begin{array}{l}\text { University of } \\
\text { Waikato }\end{array}$ & $\begin{array}{l}\text { GNU General } \\
\text { Public License }\end{array}$ & http://www.greenstone.org/ \\
\hline E Prints & $\begin{array}{l}\text { University of } \\
\text { Southampton }\end{array}$ & $\begin{array}{l}\text { GNU General } \\
\text { Public License }\end{array}$ & http://www.eprints.org/ \\
\hline Invenio & $\begin{array}{l}\text { CERN Document } \\
\text { Server } \\
\text { Software } \\
\text { Consortium }\end{array}$ & $\begin{array}{l}\text { GNU General } \\
\text { Public License }\end{array}$ & http://invenio-software.org/ \\
\hline
\end{tabular}

Source: Author compiled

To develop the digital library for EUSL Library, DSpace was selected. DSspace is an advanced digital repository software created as a joint project of MIT libraries and the Hewlett-Packard Company. DSpace digital repository software is freely available as open source software under the terms of the BSD distribution license.

A list of important feature of $\mathrm{D}$-space is given below:

- DSpace accepts all kinds of digital formats for submission.

- Customize the metadata as per the requirements.

- Statistics for administrator usage and usage statistics reports can be generated. The reports can also be made public or restricted to administrator access only.

- Authority control for metadata fields.

- RSS feeds of new items available for collections and communities. 
- Subscribe to collections in order to be altered when items appear in a particular collection.

- Web application is available in over twenty languages.

- DSpace has a very good web interface and the ability to manage various file formats which helps in developing a blended repository.

- Allows import and export for Communities, Collections and Items.

- Hierarchy to manage contents (i.e., Communities, Collections and Items)

- By default, DSpace stores item Metadata in the Dublin Core Metadata Schema. This ensures data can be exchanged with other standards compliant system, such as MARC 21.

- Compliant with the OAI-PMH.

\section{Step 5 - Metadata Creation}

Metadata, as a form of data affixed to other data and describes data about data, provides context, It is vital for accurate data interpretation and use by both humans and machines and metadata can be available in various standards (Greenberg Jane, 2017). DSpace uses Dublin Core metadata schema which is available by default when the DSpace software is installed and configured. Dublin Core is an internationally recognized metadata standard used to describe a resource. The study has developed a core set of metadata elements for the project-related documents and other documents to accommodate them in the repository especially for Palm Leaf and Manuscripts, Periodicals and Rare collections.

\section{Step 6 - Customizing Item Preview Interface}

There are several interfaces available in the default digital repository, this specialized repository has restricted access to the system administrator, submission process and end-user/public interfaces (Figure 1). The end-user or public interface supports searching and retrieval link of rare collection items by browsing or searching the metadata on a web browser. With the bulk amount of collected data, the Ceylon Collections were divided further according to the Dewey Decimal Classification (DDC) system.

Digitization process is depicted in Figure 2. 


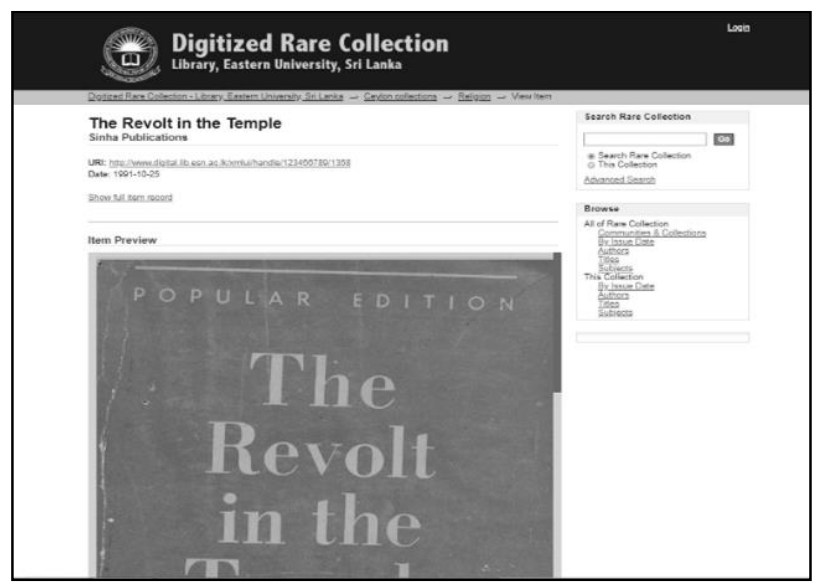

Source: http://www.digital.lib.esn.ac.lk/xmlui/

Figure 1. Item preview interface

\section{Other Requirements}

\section{Manpower}

The success of any implementation depends on the effective functioning of the personnel. Implementing ICT related projects like digital collection requires very skilled, creative and technologically sound manpower. The project is initiated by two professionals without any training on functioning and technicalities of DSpace. After testing the server; it was successfully implemented the digital collection and today its collection is totaling to 2000 items. Two library support staff members were trained and appointed for scanning and saving the files in requested file format.

\section{Financial Support}

Implementing ICT project and its maintenance requires strengthen collaborative effort of librarians, IT specialists and employees. Especially this project has a very successful collaboration between librarians, IT specialists and employees. Since the technological infrastructure was available at the library, the start-up cost was literally to zero. The software selected for implementing the project was DSpace, which is free open source software was also a cost saving option. Since the library IT professional themselves acquire very much technical knowledge of functioning of DSspace that also saved the initial training costs. Hence, by utilizing the existing ICT infrastructure, manpower and collaborating with other divisions at EUSL library, it is clear that the initial zero cost. 
Journal of the University Librarians Association of Sri Lanka, Vol.21, Issue 2, July 2018, 123-139 DOI: https://doi.org/10.4038/jula.v21i2.7921

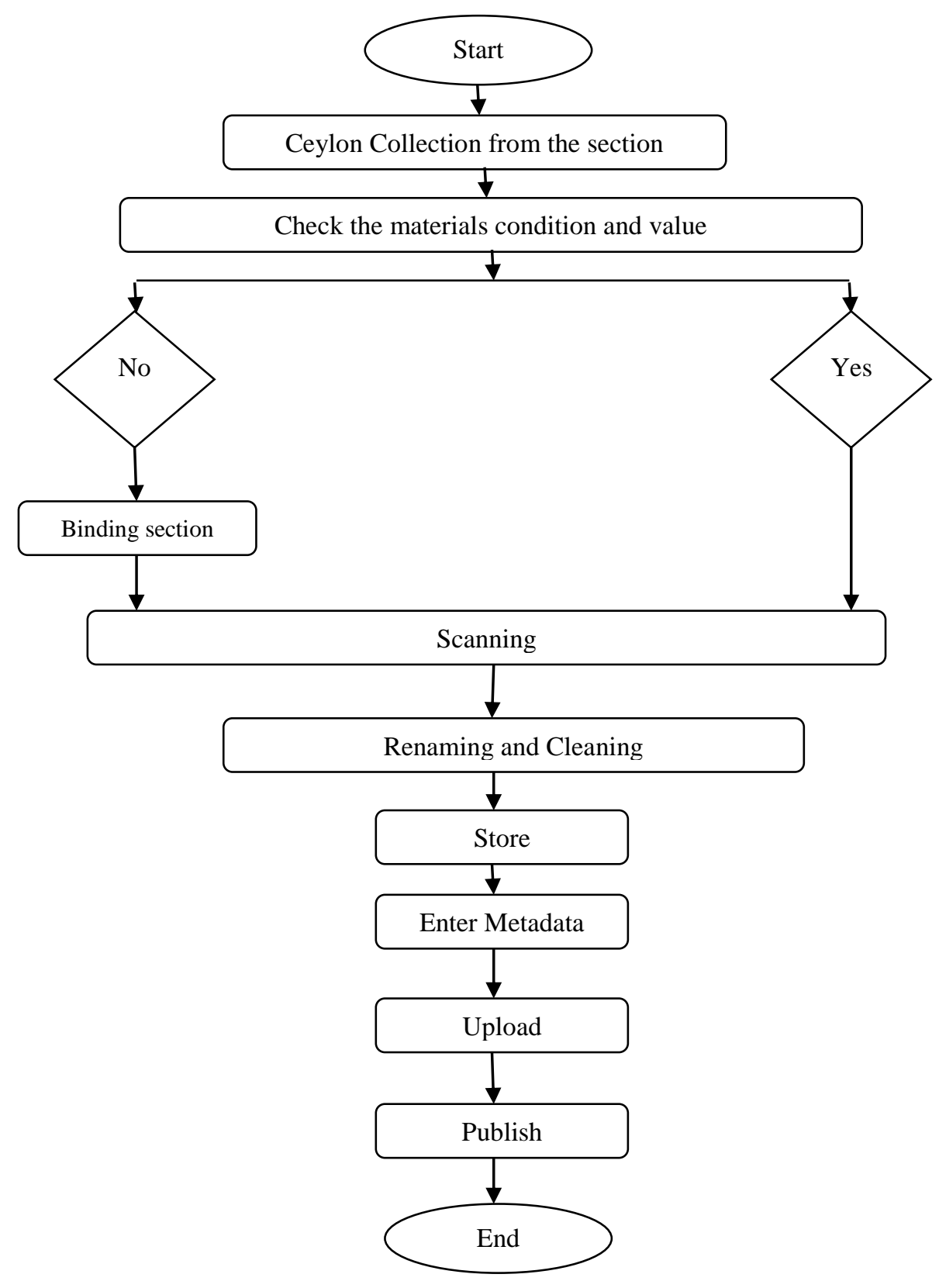

Source: Author compiled

Figure 2. Digitization process 


\section{Copyright Policy}

Digital repository access and archive copyright polices are current discussion areas of digital age. Library staff is responsible for getting the copyright clearance from the publishers, so that there should not be any issues when the digital collection moves to the Internet. Where is not possible to get the copyright clearance, such materials were restricted from viewing and downloading. In such cases an option was given to the users to request a copy.

\section{Results and Discussion}

By the observation and focus group interview, it was found that, the digitization process is very important and essential when considering the conditions of Ceylon Collections available in EUSL library. Results obtained through the research are given below according to the specific objectives.

\section{Specific Objective 1}

Conservation and preservation of valuable Ceylon Collections by means of digitization for researchers and academics who engaged in this field and for the use of future generation.

Digitization is one of the efficient ways of preservation of library documents. Especially, it enables and facilitates with a safe place for digital collections and makes preventive conservation of materials from various factors. Also it is vital to know that the visibility of the academics and researchers regards new digital service. The following Table capture the visibility data of the Ceylon Collection users' behaviour.

During the six-month period, 1352 people visited the site. $34.72 \%$ of users were identified as new visitors. On average, 06.23 time on site accessed during each visit. Direct traffic to the site was $59.03 \%$, with $24.12 \%$ being referred access. In order, the top access countries to the site were: (i) Sri Lanka, (ii) India and (iii) Malaysia. As mentioned above, one would expect that users would spend more time on the site in the future, as a result of additional and valuable content. 
Table 3. Visibility of Ceylon Collection

\begin{tabular}{lll}
\hline \multicolumn{1}{c}{ Variable Measured } & \multicolumn{1}{c}{$\begin{array}{c}\text { Period } \\
\text { January - June 2018 }\end{array}$} \\
\hline Visits & 1352 \\
Page Visits & 6841 & \\
New Visits & 34.72 & \\
Average time on site & 06.23 & 59.03 \\
Direct traffic & 18.06 \\
Referring sites & 22.91 \\
Search engine & பொருளியல், இந்து மதம், சமூக அறிவியல் \\
Top usage key terms & Sri Lanka, India, Malaysia \\
Top usage Countries & \multicolumn{2}{c}{ Source: Google Analytics }
\end{tabular}

Specific Objective 2

Compiling bibliographic details of Ceylon Collections which showcase their value and importance.

These specific Ceylon Collections are desirable to access more easily than reading printed and old documents. Therefore, it is essential to digitize those Ceylon Collections which enable the users to access online. Also, it enhances the accessibility and readability of users as finding and reading the original documents is much more difficult for users. By digitizing the Ceylon collections, it could be maintained as a digital repository of Ceylon collections which are capable to access through our library website (Figure 3). Thus, every user would able to access those Ceylon collections.

From the digital repository, the Ceylon Collections could be browsed by title, author, subjects and issue date. The subjects including in the Ceylon Collections are arts and recreation, computer science, information and general works, history and geography, language, literature, philosophy and psychology, religion, science, social sciences and technology. It could be browsed and filtered by alphabetical ascending or descending order and manage the numbers of display on the page too. There is a search option and it could be easy to find out the right document according to the user needs. The users could able to do advanced search and further they could filter the documents which they need. It could be able to view the full item record 
including all identifiers of metadata of a record of the document as all details of the document available in it (Figure 4).

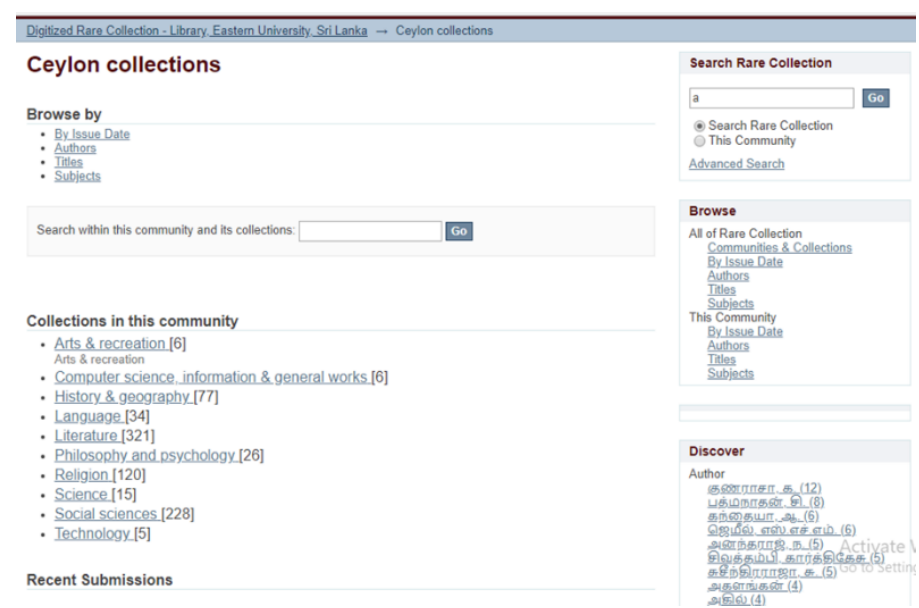

Source: http://www.digital.lib.esn.ac.lk

\section{Figure 3. Bibliographic details of Ceylon Collections}

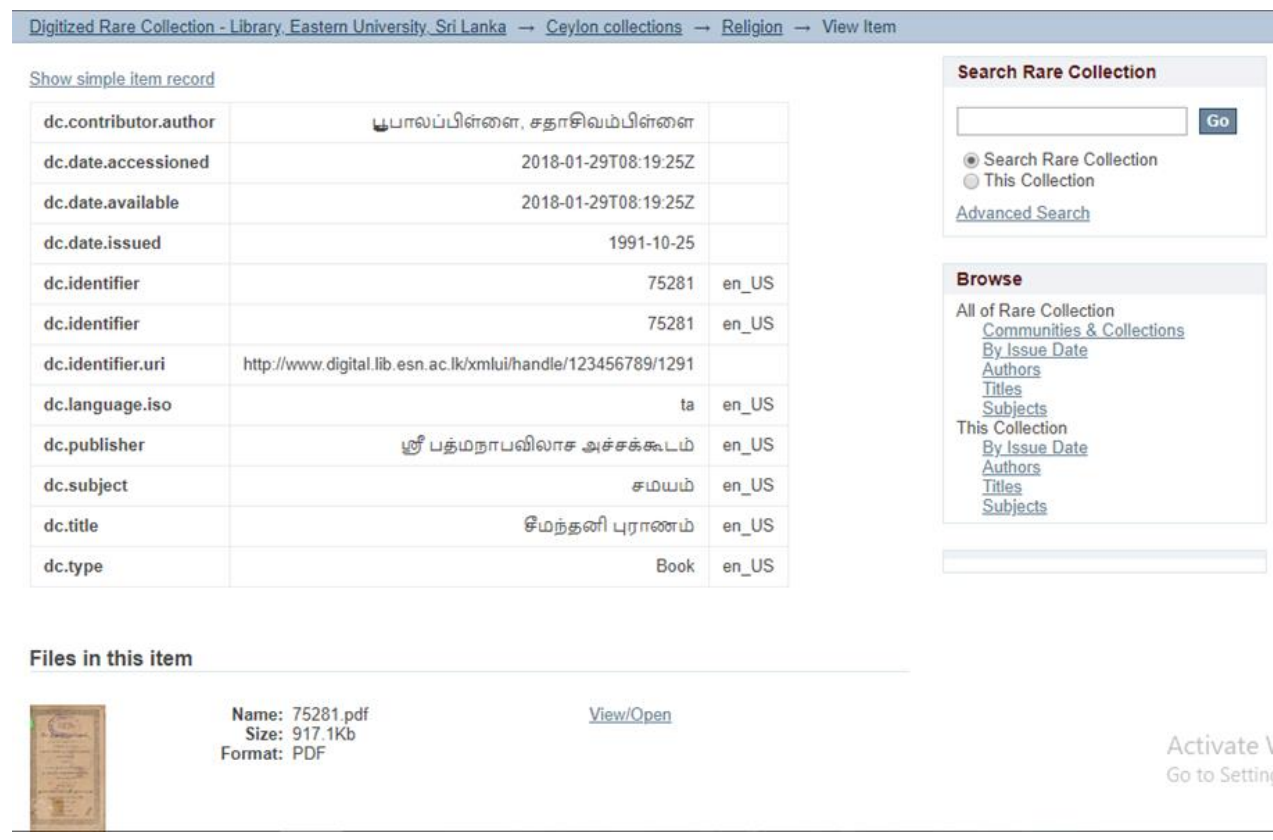

Source: http://www.digital.lib.esn.ac.lk

Figure 4. Full item record of a document 


\section{Specific Objective 3}

Challenges during the process of digitization of Ceylon collections.

Even though, the EUSL library has faced several challenges during the process of digitization the processes were in success. The challenges faced by the team are as follows;

- Size of data: Once digitized the collection, the size of data is more and space was not enough. And also, sophisticated storage media is recommended to ensure the usefulness and retain ability.

- Type of documents: It is essential to select only the exact documents which are used frequently by researchers. If the documents are not frequently used it is uneconomical to digitize them even they have research validity. It is recommended to work with the subject expertise, to select the appropriate list for digitization without concentrating on the whole collection.

- Technological problems: The technology should be well-suited with various systems. The technology is changing day to day and vast revolution on changes occur. The digitized materials become unreadable if the changes occur in other devices and resulted in a loss of data. And digital media is also affected by light, heat, moisture, insect, acid content and air pollution and digital storage media always under threat of above factors. Therefore, it is recommended to establish a good environment for digital data and use compatible devices to ensure continuous readability.

- Copyrights issues: Before, digitization it is essential to get the permission from the authors of materials which are going to be digitized to avoid creating problems. Because of copyright issues, the digitized collections are in-house accessible only. The main target for the digitization is in preservation perspective rather than accessible for everyone as the precious information resource must be taken care by the librarians or custodians.

- Selection of suitable equipment: The scanner must be a well appropriate one. Otherwise problems such as mechanical stress and clarity problems during scanning. Therefore, suitable personal should be selected for scanning. The manual book scanners and overhead scanners are more suitable for the kind of unique collections like Ceylon collections which are more fragile.

- Limitation of human resources: It's an essential need to have well trained professional or staff for the scanning, digitization processes and 
documentation. Because the processes should be made with much more of the documents, they have to be well trained before the processes. Lack of enough human resources or shortage of human resources for routine duties of the library creates a limitation to the digitization task.

\section{Conclusion and Recommendations}

The EUSL library has completed to conserve and preserve the Ceylon Collections by means of digitization which ensure the collections longlasting than ever. The users and community of EUSL library are able to access valuable collections of written heritage of Sri Lanka through the digitized Ceylon Collections. Therefore, it provides a multidimensional and multifaceted contribution to the written heritage of those collections.

The challenges during the process of digitization such as data size (space), lack of trained professionals, proper equipment and mechanical damages could be excluded by selection of an appropriate size of server and well suited scanner; arranging training programmes for staff; proper handling procedures during digitization and finding suitable funding agent for the digitization.

\section{References}

Brantl, M. and Schafer, I. (2010). Challenges and Experiences in the Mass Digitization of Manuscripts and Rare Books at the Bavarian State Library. Paper presented at the International Conference on Digital Imaging of Ancient Textual Heritage: Technological Challenges and Solutions. Helsinki, Finland.

Chattopadhyay, S. (2006). Digital preservation in the twenty first century: concept, needs, problems and solutions. Paper presented at the 4th convention PLANNER held at Mizoram University, Aizawl.

Dilroshan, T. L. C. (1995). Identification of problems faced by university libraries in the process of automation: With special reference to the libraries of Moratuwa and Colombo Universities. Sri Lanka Journal of Librarianship and Information Management, 1(2), 82-97.

Gangabadachchchi, V. \& Amarasiri, M. S. U. (2006). Digital collections building initiatives of National Library and Documentation Centre. Sri 
Lanka. Journal of Librarianship and Information Management. 2(1), 38-43.

Hindagolla, M. (2013). Digital library development and its sssues in Sri Lanka: Review of literature. Modern Social and Cultural Studies, (57), 89-103. Retrieved from http://ci.nii.ac.jp/naid/120005359183/

Greenberg, J. (2017) Sharing restricted data: Challenges, protocols and implications for digital libraries. Keynote address at the joint 8th ALIEP Conference/ $19^{\text {th }}$ ICADL Conference, Thailand. Retrieved from https://cci.drexel.edu/mrc/2017/11/14/jane-greenberg-presenting-keynote-at-the-joint-8th-a-liepconference19th-icadl-conference-2/

IFLA (2014). Guidelines for planning the digitization of rare book and manuscript collections. Hague: International Federation of Library Associations and Institutions. Retrieved from https://www.ifla.org/files/assets/rare-books-and-manuscripts/rbmsguidelines/guidelines-for-planning-digitization.pdf

Jenkins, F. W. (2012). Purposes and challenges of digitized collections for the humanities in academic libraries. Library Student Journal, 7(6). Retrieved from http:// www.librarystudentjournal.org/index.php/sj/article/view/310/361

Kodikara, R. C., Seneviratne, T. M., \& Punchihewa, C. N. D. (2014). Beyond the Walls: Outreach Initiatives in Library, University of Moratuwa. Sri Lankan Journal of Librarianship and Information Management, 5(2), 10-22. https://doi.org/10.4038/sllim.v5i2.7155

Mittal, R., \& Mahesh, G. (2008). Digital libraries and repositories in India: An evaluative study. Program, 42(3), 286-302. https://doi.org/10.1108/00330330810892695

Open Society Institute. (2004). A guide to institutional repository software (3rd ed.) Retrieved from http://www.budapestopenaccessinitiative.org/resources/guidetoinstitutional-repository-software

Ranasinghe, P., \& Dilruk, W. M. T. (2013). Preserving Sri Lanka's traditional manuscript culture: role of the palm leaf digitization project of the Faculty of Social Sciences, University of Kelaniya. Paper presented at IFLA World Library and Information Congress, Singapore.

Ranjith Kumar. (2014). Research Methodology: Selecting a study design. New Delhi: SAGE Publications India Pvt. Ltd. 